\title{
Cochrane
}

Library

Cochrane Database of Systematic Reviews

\section{Methylxanthines for prolonged non-specific cough in children} (Review)

Chang AB, Halstead RAP, Petsky HL

Chang AB, Halstead RAP, Petsky HL.

Methylxanthines for prolonged non-specific cough in children.

Cochrane Database of Systematic Reviews 2005, Issue 2. Art. No.: CD005310.

DOI: 10.1002/14651858.CD005310.pub2.

www.cochranelibrary.com 
TABLE OF CONTENTS

ABSTRACT

PLAIN LANGUAGE SUMMARY

BACKGROUND

OBJECTIVES

METHODS

RESULTS

DISCUSSION

AUTHORS' CONCLUSIONS

ACKNOWLEDGEMENTS

REFERENCES

CHARACTERISTICS OF STUDIES

APPENDICES

WHAT'S NEW

HISTORY

CONTRIBUTIONS OF AUTHORS

DECLARATIONS OF INTEREST

SOURCES OF SUPPORT

INDEX TERMS 
[Intervention Review]

\section{Methylxanthines for prolonged non-specific cough in children}

Anne B Chang1', Ria AP Halstead 2 , Helen L Petsky³

${ }_{1}^{1}$ Royal Children's Hospital, Brisbane and Menzies School of Health Research, CDU, Darwin, Queensland Children's Respiratory Centre and Queensland Children's Medical Research Institute, Brisbane, Australia. ${ }^{2}$ Respiratory Medicine, Royal Children's Hospital, Brisbane, Australia. ${ }^{3}$ Department of Respiratory Medicine, Royal Children's Hospital, Brisbane, Australia

Contact: Anne B Chang, Royal Children's Hospital, Brisbane and Menzies School of Health Research, CDU, Darwin, Queensland Children's Respiratory Centre and Queensland Children's Medical Research Institute, Herston Road, Herston, Brisbane, Queensland, 4029, Australia. annechang@ausdoctors.net, Anne.chang@menzies.edu.au.

Editorial group: Cochrane Airways Group.

Publication status and date: New search for studies and content updated (no change to conclusions), published in Issue 12, 2010.

Citation: Chang AB, Halstead RAP, Petsky HL. Methylxanthines for prolonged non-specific cough in children. Cochrane Database of Systematic Reviews 2005, Issue 2. Art. No.: CD005310. DOI: 10.1002/14651858.CD005310.pub2.

Copyright @ 2010 The Cochrane Collaboration. Published by John Wiley \& Sons, Ltd.

\section{A B S T R A C T}

\section{Background}

Non-specific cough is defined as non-productive cough in the absence of identifiable respiratory disease or known aetiology. It is commonly seen in paediatric practice. These children are treated with a variety of therapies including a variety of asthma medications. Methylxanthines, the main medication used for paediatric asthma for many decades in Western countries, is still widely used in nonWestern countries. Also, methylxanthines have other pharmacological properties and their bronchodilator effect is only modest.

\section{Objectives}

To evaluate the efficacy of methylxanthines in treating children with non-specific cough.

\section{Search methods}

The Cochrane Register of Controlled Trials (CENTRAL), the Cochrane Airways Group Specialised Register, MEDLINE and EMBASE databases were searched by the Cochrane Airways Group. The latest searches were performed in October 2010.

\section{Selection criteria}

All randomised controlled trials comparing methylxanthines with a placebo medication in treating children with non-specific cough.

\section{Data collection and analysis}

Results of searches were reviewed against pre-determined criteria for inclusion. No eligible trials were identified and thus no data were available for analysis. Four small non-randomised controlled trials were reported.

\section{Main results}

No randomised controlled trials that examined the efficacy of methylxanthines in the management of prolonged non-specific cough in children were found. In the non randomised trials above, a significant effect was seen within 2-14 days of therapy.

\section{Authors' conclusions}

There is currently an absence of reliable evidence to support the routine use of methylxanthines for symptomatic control of non-specific cough in children. If methylxanthines were to be trialed in children with prolonged non-specific cough, cohort data (thus limited) suggest a clinical response (subjective cough severity) would be seen within two to five days (and certainly within 14 days) of therapy. However 
methylxanthine use has to be balanced against the well known risk of toxicity and its low therapeutic range in children. Further research examining the efficacy of this intervention is needed.

\section{PLAIN LANGUAGE SUMMARY}

\section{Methylxanthines for prolonged non-specific cough in children}

Children with non-specific cough (dry and non-productive cough without any other respiratory symptom, sign or systemic illness) are commonly treated with a variety of medications to manage the symptom of cough. This review examined whether there was any evidence for using methylxanthines in children with non-specific cough. There were no randomised controlled trials that assessed methylxanthines for prolonged non-specific cough in children. In four non-randomised controlled studies, the researchers described that dramatic improvements in cough were seen within 2-14 days of taking oral theophylline. However, this is possibly a placebo and/or time period effect. There is no RCT evidence to support the routine use of methylxanthines for the symptom of non-specific cough in children. Further research examining the effects of methylxanthines using child appropriate cough outcome measures are needed. 


\section{B A C K G R O U N D}

Cough is the most common symptom presenting to general practitioners (Britt 2002; Cherry 2003) and causes significant anxiety to parents (Cornford 1993). Worldwide the desire to reduce the impact of the symptom of cough is reflected in the billions of dollars spent on over the counter cough and cold medications. Non-specific cough has been defined as non-productive cough in the absence of identifiable respiratory disease or known aetiology (Chang 2001). While some children with chronic non-specific cough have asthma, the majority do not (Chang 1999; McKenzie 1994).

Methylxanthines are pharmaceutically available as theophylline, aminophylline and caffeine. More recently, methylxanthine derivatives (pentoxifylline, propentofylline and pentiphylline) are used as neuro protective (Bath 2004) or vascular agents and not for diseases of the respiratory tract. Theophylline and aminophylline are currently the methylxanthines available for the respiratory tract. Currently, these medications are not commonly used in the majority of developed Western countries but are still widely used in the treatment of asthma in developing countries. In developed countries, before corticosteroids became the main therapeutic option for the management of paediatric asthma, these medications were previously extensively used in the management of asthma (Skoner 2002).

The frequently cited studies on 'cough variant asthma' in the 1970 s and 80s used theophylline (amongst other agents that included major tranquillisers) (Chang 1999) which was the main therapeutic agent for asthma of the era (Skoner 2002). However, methylxanthines have many other pharmacological properties and their bronchodilator effect is only modest (Rabe 1998). The effects of methylxanthines on the respiratory tract include immunomodulation, decrease in diaphragmatic muscle fatigue, increase mucociliary clearance, and improvement of central hypoventilation (Rabe 1998; Vassallo 1998). Indirectly its potential respiratory benefits include an "increase in endogenous secretion of cortisol, stimulation of release of endogenous catecholamines; positive inotropic effect on the heart and as a mild diuretic" (Ram 2002). Thus methylxanthines may have an effect on abnormal cough that is separate to its modest bronchodilator effect. Indeed a randomised controlled trial in adults showed that theophylline decreased cough associated with ACE inhibitors (Cazzola 1993). Use of any medication has to be balanced against possible harm/ adverse events. The use of methylxanthines in children has been associated with impaired neuro-cognitive function in children (Skoner 2002) (although there is some controversy (Stein 1996)). Also, they have a narrow therapeutic range and toxicity effects including seizures. Methylxanthines also potentially impair the developing nervous system through its non specific inhibition on adenosine receptors (Millar 2004).

Thus although methylxanthines have a range of recognised benefits for the respiratory system (Rabe 1998) including a possible impact on cough, their associated adverse events needs to be considered. A systematic review of the benefits (or otherwise) of methylxanthines on chronic non-specific cough would thus be useful to help guide clinical practice.

\section{OB JECTIVES}

To evaluate the efficacy of methylxanthines in treating children with non-specific cough.

\section{METHODS}

\section{Criteria for considering studies for this review}

\section{Types of studies}

All randomised controlled trials comparing methylxanthines (theophylline, aminophylline, caffeine) with a placebo medication for cough, where cough is not primarily related to an underlying respiratory disorder such as cystic fibrosis, asthma, suppurative lung disease etc.

\section{Types of participants}

Children with chronic ( $>3$ weeks) non-specific cough (dry and nonproductive cough without any other respiratory symptom, sign or systemic illness).

Exclusion criteria: cough related to mycoplasma, pertussis and chlamydia, presence of underlying cardio-respiratory condition, current or recurrent wheeze ( $>2$ episodes), presence of other respiratory symptoms (productive cough, haemoptysis, dyspnoea), presence of other respiratory signs (clubbing, chest wall deformity, respiratory noises such as wheeze on auscultation and other adventitious sounds), presence of any sign of systemic illness (failure to thrive, aspiration, neurological or developmental abnormality), presence of lung function abnormality.

\section{Types of interventions}

All randomised controlled comparisons of methylxanthines (theophylline, aminophylline, caffeine) with placebo. Trials only comparing two or more medications without a placebo comparison group were not included. Trials that included the use of other medications or interventions were included if all participants had equal access to such medications or interventions.

\section{Types of outcome measures}

\section{Primary outcomes}

Proportions of participants who were not cured or not substantially improved at follow up (clinical failure).

\section{Secondary outcomes}

1. Proportions of participants who were not cured at follow up

2. Poportions of participants who not substantially improved at follow up,

3. Mean difference in cough indices (cough diary, cough frequency, cough scores),

4. Proportions experiencing adverse effects of the intervention, (e.g. seizures, school performance etc),

5. Proportions experiencing complications e.g.. requirement for medication change, etc.

It was planned that the proportions of participants who failed to improve on treatment and the mean clinical improvement would be determined using the following hierarchy of assessment measures (i.e. where two or more assessment measures are reported in the same study, the outcome measure that is listed first in the hierarchy will be used).

i) Objective measurements of cough indices (cough frequency, cough receptor sensitivity). 
ii) Symptomatic (Quality of life, Likert scale, visual analogue scale, level of interference of cough, cough diary) - assessed by the patient (adult or child)

iii) Symptomatic (Quality of life, Likert scale, visual analogue scale, level of interference of cough, cough diary) - assessed by the parents/carers.

iv) Symptomatic (Likert scale, visual analogue scale, level of interference of cough, cough diary) - assessed by clinicians.

v) Relevant airway markers consistent with inflammation.

\section{Search methods for identification of studies}

\section{Electronic searches}

The following topic search strategy was used to identify relevant randomised controlled trials in the bibliographic databases:

("cough" OR "bronchitis", all as [textword] or [MeSH ]) AND ("theophylline" OR "aminophylline" OR "caffeine" OR "methylxanthines" OR "methylxanthine") AND ("child" OR "children"; all as [textword] or [MeSH ])

For the full strategies please see Appendix 1. The latest searches were conducted in October 2010

Trials were identified from the following sources:

1. The Cochrane Central Register of Controlled Trials (CENTRAL)

2. The Cochrane Airways Group Specialised Register of Trials.

3. MEDLINE (1950 - current). Topic search strategy combined with the RCT search filter as outlined in the Airways Group module.

4. EMBASE (1980 - current). Topic search strategy combined with the RCT search filter as outlined in the Airways Group module.

\section{Searching other resources}

5. The list of references in relevant publications.

6. Written communication with the authors of trials included in the review.

\section{Data collection and analysis}

\section{Selection of studies}

From the title, abstract, or descriptors, all three reviewers independently reviewed literature searches to identify potentially relevant trials for full review. Searches of bibliographies and texts were conducted to identify additional studies. From the full text using specific criteria, the two reviewers (AC, HP) independently selected trials for inclusion. Agreement would have been measured using kappa statistics. It was planned that disagreement be resolved by third party adjudication $(\mathrm{RH})$.

\section{Data extraction and management}

Trials that satisfied the inclusion criteria were reviewed and the following information would have been recorded: study setting, year of study, source of funding, patient recruitment details (including number of eligible subjects), inclusion and exclusion criteria, other symptoms, randomisation and allocation concealment method, numbers of participants randomised, blinding (masking) of participants, care providers and outcome assessors, dose and type of intervention, duration of therapy, cointerventions, numbers of patients not followed up, reasons for withdrawals from study protocol (clinical, side-effects, refusal and other), details on side-effects of therapy, and whether intention- to-treat analyses were possible. Data would have been extracted on the outcomes described previously. It was planned that further information be requested from the authors where required.

\section{Assessment of risk of bias in included studies}

Studies included in the review would have undergone quality assessment performed independently by two review authors using the 'risk of bias' tool in Revman 5.

\section{Data synthesis}

The data would have been analysed as follows. For the dichotomous outcome variables of each individual study, relative and absolute risk reductions calculated using a modified intentionto-treat analysis. This analysis assumes that children not available for outcome assessment have not improved (and probably represents a conservative estimate of effect). An initial qualitative comparison of all the individually analysed studies would have examined whether pooling of results (meta-analysis) was reasonable. This would have taken into account differences in study populations, inclusion/exclusion criteria, interventions, outcome assessment, and estimated effect size.

The results from studies that met the inclusion criteria and reported any of the outcomes of interest would have been included in the subsequent meta-analyses. The summary weighted risk ratio and 95\% confidence interval (fixed effects model) would have been calculated using the inverse of the variance of each study result for weighting (Cochrane statistical package, REVMAN version 5). For cross-over studies, mean treatment differences would have been calculated from raw data, extracted or imputed and entered as fixed effects generic inverse variance (GIV) outcome, to provide summary weighted SD unit difference and 95\% confidence intervals. In crossover trials, only data from the first arm would be included in meta analysis if data were combined with parallel studies (Elbourne 2002). Numbers needed to treat (NNT) would have been calculated from the pooled OR and its $95 \% \mathrm{Cl}$ applied to a specified baseline risk using an online calculator (Cates 2003). This calculator converts the risk in the placebo group to the corresponding odds, applies the OR to estimate the odds in the treated group, and converts that odds to the corresponding risk and calculates the risk difference, the inverse of which is the NNT. The cough indices would have been assumed to be normally distributed continuous variables so the mean difference in outcomes can be estimated (weighted mean difference). If studies reported outcomes using different measurement scales, the standardised mean difference would have been estimated. Any heterogeneity between the study results would have been described and tested to see if it reached statistical significance using a chi-squared test. The $95 \%$ confidence interval estimated using a random effects model would have been included whenever there are concerns about statistical heterogeneity.

\section{Subgroup analysis and investigation of heterogeneity}

An a priori sub-group analysis was planned for children aged less than 7 years and 7 years and above.

\section{Sensitivity analysis}

1. Differences in the medications used in the intervention and comparison groups;

2. Differences in outcome measures;

3. Analysis using random effects model; 
4. Analysis by "treatment received";

5. Analysis by "intention-to-treat"; and

6. Analysis by study design-parallel and cross over studies

\section{RE S U L T S}

\section{Description of studies}

In the original review, the Airways Group specialised register/ search identified 350 potentially relevant titles. After assessing the abstracts, 16 studies were considered for inclusion into review including 3 non-English articles (Polish, German and Spanish). None of the studies fulfilled study criteria. The 2009 and 2010 searches revealed 153 abstracts, of which all were excluded. A pharmaceutical brochure outlining the benefits of a theobromine containing medication (Anycough) for cough was identified during a conference for the 2010 update. The authors wrote to the company but no response was received and no published data could be found.

\section{Risk of bias in included studies}

Not applicable.

\section{Effects of interventions}

In the absence of appropriate RCTs, four other paediatric papers (Cloutier 1981, Konig 1981, Yahav 1982; Hannaway 1982) that specifically reported on the effect of theophylline on cough in children were also reviewed. All four studies (see excluded table) were non randomised controlled trials and all reported a rapid response, mostly within two to five days and one study (Konig 1981) used theophylline for up to 14 days. One adult study (Cazzola 1993) that was a double blind RCT was also reviewed; in this trial, complete remission in cough was reported in eight of the ten adults after two weeks of oral theophylline. No relevant papers have been identified in update searches.

\section{DISCUSSION}

No randomised controlled trials comparing methylxanthines with a placebo in children with non-specific cough were identified. Cohort studies were thus reviewed and while no conclusion about efficacy of theophylline for non specific cough can be made, these studies show that the 'time response' was short i.e. within two days to two weeks. These early studies on the relationship between cough and asthma also show that in many children, other symptoms of asthma (dyspnoea on exertion (Cloutier 1981; Konig 1981), chest pain on exertion (Konig 1981), spirometry abnormalities and/or auscultation abnormalities (Hannaway 1982; Yahav 1982) were present. However some children in these studies had non-specific cough, and did not have clinical features of classical asthma yet all responded to theophylline. However this has to be interpreted in the context of methodological problems in studies with cough as an outcome measure, specifically the large placebo effect, biased subjective reporting, and period effect (Chang 1999).

The pharmacological properties of methylxanthines exceed that of its modest bronchodilator effect (Rabe 1998) and although some of the non-RCT results emphasised its bronchodilator effect, it is unlikely that the rapid response to theophylline was purely related to this effect as the bronchodilator effect of theophylline is only modest.

Given the morbidity associated with chronic cough in children, there is a need for the evaluation of the efficacy of theophylline on non-specific cough in children. Its use however has to be balanced with its associated adverse events as briefly described above (background section).

\section{AUTHORS' CONCLUSIONS}

\section{Implications for practice}

With the lack of evidence, the routine use of methylxanthines in treating children with non-specific cough cannot be recommended. If methylxanthines were to be trialed in these children, current (but old and limited) cohort data suggest a clinical response (subjective cough severity) usually occurs within two to five days of therapy and definitely within two weeks. However the use of methylxanthines in children with non-specific cough has to be balanced against the well known risk of toxicity and its narrow therapeutic range in children.

\section{Implications for research}

Randomised controlled trials of methylxanthines to determine the effectiveness in treating children with non-specific cough are clearly needed. Trials should be parallel studies and double blinded, given the known problems in studying cough, specifically the large placebo and time period effects (Chang 1999). Based on cohort data, a short trial of two weeks would suffice. Outcome measures for the clinical studies on cough should be clearly defined using validated subjective data and supported by objective data when possible.

\section{ACKNOWLEDGEMENTS}

We thank Toby Lasserson, Chris Cates, Michael McKean and Emma Welsh from the Airways Group for their advice, supportive role and comments to the protocol and review. We are also very grateful to Elizabeth Arnold for performing the relevant searches and obtaining the articles. We also thank Lech Leskiewicz for translation of German and Polish articles, and Patricia Valery for Spanish translation. Finally we thank Susan Hansen for performing the searches for this update. 


\section{R E F E R E N C E S}

\section{References to studies excluded from this review}

Bose 1987 \{published data only\}

Bose B, Cater JI, Clark RA. A once daily theophylline preparation in prevention of nocturnal symptoms in childhood asthma. European Journal of Pediatrics 1987;146(5):524-7.

\section{Cazzola 1993 \{published data only\}}

Cazzola M, Matera MG, Liccardi G, De Prisco F, D'Amato G, Rossi F. Theophylline in the inhibition of angiotensin-converting enzyme inhibitor-induced cough. Respiration 1993;60(4):212-5.

\section{Chyrek 1988 \{published data only\}}

Chyrek-Borowska S, Szymanski W, Niklinska B, Obrzut D, Michalska I. Clinical evaluation of the effectiveness of aminophylline in treating bronchial asthma and spastic bronchitis [Ocena kliniczna skutecznosci aminofiliny w terapii astmy oskrzelowej i spastycznego niezytu oskrzeli]. Polski Tygodnik Lekarski 1988;43:1377-9.

\section{Cloutier 1981 \{published data only\}}

Cloutier MM, Loughlin GM. Chronic cough in children: a manifestation of airway hyperreactivity. Pediatrics 1981;67:6-12.

\section{Hannaway 1982 \{published data only\}}

Hannaway PJ, Hopper GDK. Cough variant asthma in children. JAMA 1982;247:206-8.

\section{Konig 1981 \{published data only\}}

Konig P. Hidden asthma in children. American Journal of Diseases of Children 1981;135:1053-5.

\section{Perez 1994 \{published data only\}}

Perez NJ, Serna PC. Functional and clinical evaluation of the bronchodilator effect of acebrophylline in obstructive pulmonary disease in children [Valoracion funcional y clinica del efecfto broncodilatador de la acebrofilina en la patologia pulmonar obstructiva del nino]. Investigacion Medica Internacional 1994;21(2):67-71.

Rachelefsky 1980 \{published data only\}

Rachelefsky GS, Katz RM, Mickey MR Jr, Siegel SC. Metaproterenol and theophylline in asthmatic children. Annals of Allergy 1980;45(4):207-12.

\section{Selby 1997 \{published data only\}}

Selby C, Engleman HM, Fitzpatrick MF, Sime PM, Mackay TW, Douglas NJ. Inhaled salmeterol or oral theophylline in nocturnal asthma?. American Journal of Respiratory \& Critical Care Medicine 1997;155(1):104-8.

\section{Usmani 2005 \{published data only\}}

Usmani OS, Belvisi MG, Patel HJ, Crispino N, Birrell MA, Korbonits $\mathrm{M}$, et al. Theobromine inhibits sensory nerve activation and cough. FASEB Journal 2005;19(2):231-3.
Yahav 1982 \{published data only\}

Yahav Y, Katznelson D, Benzaray S. Persistent cough - a formefruste of asthma. European Journal of Respiratory Diseases 1982;63:43-6.

\section{Additional references}

\section{Bath 2004}

Bath PMW, Bath-Hextall FJ. Pentoxifylline, propentofylline and pentifylline for acute ischaemic stroke. Cochrane Database of Systematic Reviews 2004, Issue 3. [Art. No.: CD000162.pub2. DOI: 10.1002/14651858.CD000162.pub2]

\section{Britt 2002}

Britt H, Miller GC, Knox S, Charles J, Valenti L, Henderson J, et al. Bettering the evaluation and care of health - a study of general practice activity. Australian Institue of Health and Welfare, 2002. AlHW Cat. No. GEP-10.

\section{Cates 2003 [Computer program]}

Cates C. Visual Rx. Online NNT Calculator.. http:// www.nntonline.net/: Cates C, 2003.

\section{Cazzola 1993}

Cazzola M, Matera MG, Liccardi G, De Prisco F, D'Amato G, Rossi F. Theophylline in the inhibition of angiotensin-converting enzyme inhibitor-induced cough. Respiration 1993;60(4):212-5.

\section{Chang 1999}

Chang AB. State of the art: cough, cough receptors, and asthma in children. Pediatric Pulmonology 1999;28:59-70.

\section{Chang 2001}

Chang AB, Asher MI. A review of cough in children. Journal of Asthma 2001;38(4):299-309.

\section{Cherry 2003}

Cherry DK, Burt CW, Woodwell DA. National ambulatory medical care survey: 2001 summary. Advance Data 2003;337:1-44.

\section{Cornford 1993}

Cornford CS, Morgan M, Ridsdale L. Why do mothers consult when their children cough?. Family Practice 1993;10(2):193-6.

\section{Elbourne 2002}

Elbourne DR, Altman DG, Higgins JPT, Curtin F, Worthington HV, Vail A. Meta-analyses involving cross-over trials: methodological issues. International Journal of Epidemiology 2002;31(1):140-9.

\section{McKenzie 1994}

McKenzie S. Cough - but is it asthma?. Archives of Disease in Childhood 1994;70:1-2.

\section{Millar 2004}

Millar D, Schmidt B. Controversies surrounding xanthine therapy. Seminars in Neonatology 2004;9(3):239-44. 


\section{Rabe 1998}

Rabe KF, Dent G. Theophylline and airway inflammation. Clinical and Experimental Allergy 1998;28(Suppl 3):35-41.

\section{Ram 2002}

Ram FSF, Jones PW, Castro AA, de Brito JJR, Atallah AN, Lacasse $Y$, et al. Oral theophylline for chronic obstructive pulmonary disease. Cochrane Database of Systematic Reviews 2002, Issue 3. [DOI: 10.1002/14651858.CD003902]

\section{Skoner 2002}

Skoner DP. Balancing safety and efficacy in pediatric asthma management. Pediatrics 2002;109(2 Suppl):381-92.

\section{CHARACTERISTICS OF STUDIES}

Characteristics of excluded studies [ordered by study ID]

\section{Stein 1996}

Stein MA, Krasowski M, Leventhal BL, Phillips W, Bender BG. Behavioral and cognitive effects of methylxanthines. A metaanalysis of theophylline and caffeine. Archives of Pediatrics \& Adolescent Medicine 1996;150(3):284-8.

\section{Vassallo 1998}

Vassallo R, Lipsky JJ. Theophylline: recent advances in the understanding of its mode of action and uses in clinical practice. Mayo Clinic Proceedings 1998;73(4):346-54.

\begin{tabular}{ll}
\hline Study & Reason for exclusion \\
\hline Bose 1987 & $\begin{array}{l}\text { Children had clear cut asthma defined as history of recurrent wheeze (>5 episodes). RCT in chil- } \\
\text { dren with nocturnal wheeze or cough. }\end{array}$ \\
\hline Cazzola 1993 & $\begin{array}{l}\text { RCT (double blind cross over design) in } 10 \text { adults with angiotensin converting enzyme inhibitor in } \\
\text { duced cough. After } 2 \text { weeks of theophylline complete remission was seen in } 8 \text { of the } 10 \text { adults. }\end{array}$ \\
\hline Chyrek 1988 & Adult study. Participants had clear cut asthma defined with spirometry change. \\
\hline Cloutier 1981 & $\begin{array}{l}\text { Non randomised controlled trial. } 15 \text { children with chronic cough treated with theophylline (15-20 } \\
\text { mg/kg/day). Cough resolved within 3-5 days in all children. }\end{array}$ \\
\hline Hannaway 1982 & $\begin{array}{l}\text { Non randomised controlled trial. } 10 \text { of } 32 \text { children had abnormal chest auscultation findings and } \\
\text { hence some children in cohort did not have non-specific cough. All responded to theophylline } \\
\text { (20-24 mg/kg/day). Authors reproted "dramatic response" in some children. }\end{array}$
\end{tabular}

Konig 1981

Non randomised controlled trial. 6 of the 11 children in this cohort study had dyspnoea on exertion and 2 had chest pain. Thus at least 55\% had recognisable clinical asthma. Theophylline $(16-20 \mathrm{mg} /$ $\mathrm{kg} /$ day) and metaproterenol given to all for 1-2 weeks. Authors reported "disappearance of, or great reduction" in cough.

Cross over RCT that examined the effect of a xanthine (acebrophylline for a week) compared to placebo (one week) using outcomes of cough (in addition to dyspnoea and wheeze). No washout period was described. The entry criteria (asthma and acute bronchitis) was undefined and mean baseline FEV1 was $72 \%$. Thus some children clearly had asthma rather than non-specific cough. The authors reported significantly less cough patient-days in the acebrophylline group (2\%) than in the placebo group (5.3\%).

Rachelefsky $1980 \quad \begin{aligned} & \text { RCT but clear cut asthma; defined as presence of airway reversibility on spirometry. Study com- } \\ & \text { pared metoproterenol to theophylline. }\end{aligned}$
pared metoproterenol to theophylline.

Selby 1997 RCT in adults comparing salbutamol and theophylline. No placebo.




\section{AP PEN DICES}

\section{Appendix 1. Database search strategies}

\section{CENTRAL search}

\#1 MeSH descriptor Cough explode all trees in MeSH products \#2 MeSH descriptor Bronchitis explode all trees in MeSH products

\#3 cough* in All Fields in all products $\# 4$ bronchiti* in All Fields in all products

\#5 (\#1 OR \#2 OR \#3 OR \#4)

\#6 MeSH descriptor Xanthines explode all trees in MeSH products

\#7 theophylline* or aminophylline ${ }^{\star}$ or caffeine* or methylxanthine* or methyl-xanthine* or xanthine ${ }^{\star}$ in All Fields in all products \#8 (\#6 OR \#7)

\#9 (\#5 AND \#8)

\section{MEDLINE search}

1. $\exp \mathrm{COUGH} /$

2. exp BRONCHITIS/

3. (cough\$ or bronchit\$).mp.

4. exp XANTHINES/

5. (theophylline\$ or aminophylline\$ or caffeine\$ or methylxanthine\$ or methyl-xanthine\$ or xanthine\$).tw.

6. 1 or 2 or 3

7.4 or 5

8. 6 and 7

9. ADOLESCENT/ or exp CHILD/ or exp INFANT/

10. exp PEDIATRICS/

11. (child\$ or paediat\$ or pediat\$ or adolesc\$ or infan\$ or toddler\$ or bab\$ or young\$ or preschool\$ or pre school\$ or pre-school\$ or newborn\$ or new born\$ or new-born\$ or neo-nat\$ or neonat\$).mp.

12. 9 or 10 or 11

13. 8 and 12

\section{RCT Filter}

1. (clinical trial or controlled clinical trial or randomized controlled trial).pt.

2. (randomized or randomised).ab,ti.

3. placebo.ab,ti.

4. dt.fs.

5. randomly.ab,ti.

6. trial.ab,ti.

7. groups.ab,ti.

8. or/1-7

9. Animals/

10. Humans/

11.9 not (9 and 10)

12. 8 not 11

\section{EMBASE search}

1. exp COUGHING/

2. $\exp$ BRONCHITIS/

3. (cough\$ or bronchiti\$).tw.

4. 1 or 2 or 3

5. exp Xanthine Derivative/

6. (theophylline\$ or aminophylline\$ or caffeine\$ or methyl-xanthine\$ or methylxanthine\$ or xanthine\$).tw. 
7.5 or 6

8.4 and 7

9. exp adolescent/ or exp child/ or exp infant/ or exp newborn/

10. (child\$ or paediat\$ or pediat\$ or adolesc\$ or infan\$ or toddler\$ or bab\$ or young\$ or preschool\$ or pre school\$ or pre-school\$ or newborn\$ or new born\$ or new-born\$ or neo-nat\$ or neonat\$).tw.

11. exp PEDIATRICS/

12.9 or 10 or 11

13. 8 and 12

\section{RCT Filter}

1. Randomized Controlled Trial/

2. Controlled Study/

3. randomization/

4. Double Blind Procedure/

5. Single Blind Procedure/

6. Clinical Trial/

7. Crossover Procedure/

8. follow up/

9. exp prospective study/

10. or/1-9

11. (clinica\$ adj3 trial\$).mp.

12. ((singl\$ or doubl\$ or trebl\$ or tripl\$) adj5 (mask\$ or blind\$ or method\$)).mp.

13. exp Placebo/

14. placebo\$.mp.

15. random $\$$.mp.

16. (latin adj3 square\$).mp.

17. exp Comparative Study/

18. ((control\$ or prospectiv\$ or volunteer\$) adj3 (trial\$ or method\$ or stud\$)).mp.

19. (crossover\$ or cross-over\$).mp.

20. or/11-19

21. 10 or 20

22. $\exp$ ANIMAL/

23. Nonhuman/

24. Human/

25. 22 or 23

26. 25 not 24

27.21 not 26

\section{Airways Register search}

(\#45=COUGH//) and (theophylline* or aminophylline ${ }^{\star}$ or caffeine* or methylxanthine $e^{\star}$ or methyl-xanthine* or xanthine ${ }^{\star}$ )

WHAT'S NEW

\begin{tabular}{lll}
\hline Date & Event & Description \\
\hline 14 October 2010 & New search has been performed & New literature search. No new studies were included. \\
\hline
\end{tabular}

\section{H I S T O R Y}

Protocol first published: Issue 2, 2005

Review first published: Issue 3, 2005

\begin{tabular}{lll}
\hline Date & Event & Description \\
\hline 24 March 2009 & Amended & Change of contact details \\
\hline
\end{tabular}




\begin{tabular}{lll}
\hline Date & Event & Description \\
\hline 14 January 2009 & New search has been performed & Literature search re-run; no new studies identified. \\
\hline 7 August 2008 & Amended & Converted to new review format. \\
\hline 22 February 2005 & $\begin{array}{l}\text { New citation required and conclusions } \\
\text { have changed }\end{array}$ & Substantive amendment \\
\hline
\end{tabular}

\section{CONTRIBUTIONS OF AUTHORS}

AC: initiation, formulation and writing of protocol. HP and RH: writing of protocol. For the review- AC: review and selection of studies from search, data extraction and writing of review. HP: review and selection of studies from search, and writing of review. RH: selection of studies from search and writing of review.

\section{DECLARATIONS OF INTEREST}

None known.

\section{SOURCES OF SUPPORT}

\section{Internal sources}

- Royal Children's Hospital Foundation, Australia.

\section{External sources}

- National Health and Medical Research Council, Australia.

Practitioner Fellowship support for AC (grant number 545216)

\section{INDEX TERMS}

\section{Medical Subject Headings (MeSH)}

Antitussive Agents [*therapeutic use]; Cough [ ${ }^{\star}$ drug therapy]; Xanthines [*therapeutic use]

\section{MeSH check words}

Child; Humans 